\title{
AN INTELLIGENT APPROACH OF THE FISH FEEDING SYSTEM
}

\author{
Mohammed M. Alammar and Ali Al-Ataby. \\ Department of Electrical Engineering and Electronics, \\ University of Liverpool, Liverpool, United Kingdom
}

\begin{abstract}
Fish breeding is a promising branch of farming, so the creation of tools for automation of this area is quite relevant. Feeding on fish farms is the main component of the successful functioning of such businesses. However, this process requires an in-depth preparation, as each species of fish has a different food culture, as well as various behaviours during nutrition. Moreover, in the method of feeding fish, farmers must take into account the age, size of the fish, and other characteristics. This paper contains information on the creation of a Preference testing by images processing is considered as the most effective tool that can be used to determine the sensory behaviour of an animal, which can record the eating behaviour of fish and determine the degree of their hunger, and, finally, to feed them. Moreover, small fish are shyer, which provokes their malnutrition. A smart feeding system can solve the issue of uniform the distribution of food for all fishes.
\end{abstract}

\section{KEYWORDS}

Fish Feeding, Preference testing, Fish Farming, Smart Feeding System, Methods of Fish Feeding.

\section{INTRODUCTION}

Fish farming is perspective business, which grows rapidly as it is shown in the (Fig.1). Indeed, fish feeding is one of the crucial forms of intensification of the fish-farming process [1]. Correct fish feeding in farming allows applying more dense plantings, and, thereby, increasing the fish productivity of ponds.

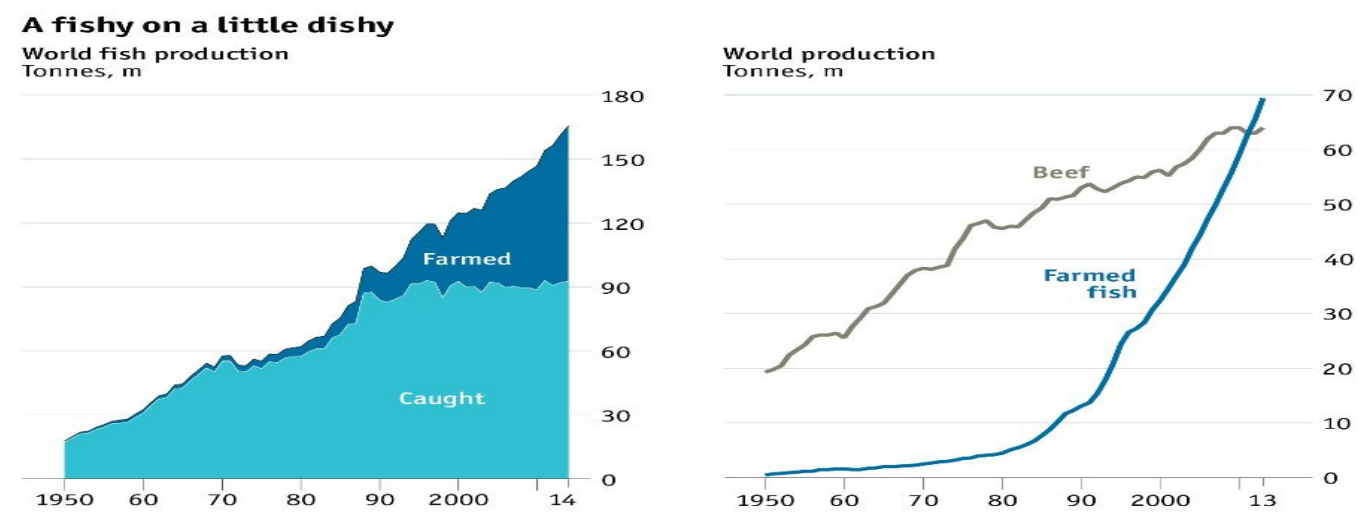

Figure 1. World fish production from 1950 to 2014 [2]

Natarajan Meghanathan et al. (Eds) : DaKM, SIPP, CCSIT, NCWMC - 2018

pp. 85-97, 2018. (C) CS \& IT-CSCP 2018

DOI : $10.5121 /$ csit.2018.81506 
Currently, fisheries around the world try to use various artificial food additives, which include all the substances necessary for the healthy growth and development of fish [1]. Feeding the fish is based on natural food, which the fish can usually find in natural water reservoirs, but on farms, this food contains more vitamins and other nutrients (Table 1) [3].

Additionally, aquaculture is the cultivation of fish and crayfishes in the closed-cycle systems [4]. Like any business or occupation, aquaculture can face many risks and challenges. Aquaculture makes it possible to grow living organisms in small volumes in conditions as close as possible to natural ones. The task of any aqua-farmer is to create such conditions in which the fish can behave comfortable and grow fast. Indeed, such growth is possible only in conditions, which are as close to natural ones as possible, and include rational feeding of all species of fish, regardless of their size and activity. More often, the natural habitat of a particular type of fish is in a much worse form, including drying up and salinization of water bodies, and pollution with industrial wastes. All this affects the natural habitat of fish. Finally, the task of the farmer is to create such conditions that the fish would feel comfortable for reproduction.

Table 1. The types of food of fish on farms [3]

\begin{tabular}{|c|c|c|}
\hline \multicolumn{2}{|c|}{ Commercialized } & \multirow{2}{*}{ Not commercialized } \\
\hline Vegetable & Animal & \\
\hline Soy meal & Poultry byproducts & Insect larvae \\
\hline Rapeseed meal & Feather meal & Single cell protein \\
\hline Sunflower meal & Shrimp and crab meal & Grasses \\
\hline Oat groats & Blood flour & Leaf protein \\
\hline Cottonseed meal & Fish silage & Vegetable silage \\
\hline \multirow[t]{7}{*}{ Wheat middlings } & Meat meal & Zooplankton (krill, etc.) \\
\hline & & Recycled wastes \\
\hline & & Yeast \\
\hline & & Phytoplankton \\
\hline & & Bacteria \\
\hline & & Algae \\
\hline & & Higher plants \\
\hline \multicolumn{3}{|c|}{ Protein (range), $\%$} \\
\hline $15-50$ & $50-85$ & $4-85$ \\
\hline
\end{tabular}

An intelligent feeding system is a quite simple and low cost which will motivate the fish farmers to acquire it. Moreover, the system can reports will convey information about the number and size of fish and their behaviour. Indicators will contain information about such categories of fish as small, medium and large ones. Based on the analysis of the size of fish and their behaviour, the farmer can draw conclusions about the correlation between these two indicators. However, an intelligent feeding system can reduce the amount of used feed by 20\% [5]. However, a false positive rate, which detects hungry fish without reasons, can feed the fished when they are full. The percentage of damage from such false feeding is not fully researched. This system will provide the estimation of the preference fish feeding by using efficient ways can observe fish behaviour and response with feeding which is significant for the farmers to improve fish production in a short period of time and at low cost.

\section{LITERATURE REVIEW}

Fish farming has gained traction in recent years due to depleting stocks in the ocean that have forced people to rear marine life in a domesticated environment. However, feeding has become a challenge since vast amounts of food are wasted that may lead to water toxicity. In any case, manual feeding is not efficiently leading to high operational costs. Development of an automatic feeding system is highly advised since it enables a farmer to automate the process thus enhancing efficiency. The Sustainable Aquaculture Feed System is a useful digital device that can identify 
fish species, sex, and count, which enables the farmer to develop a feeding program. Broadly, the automation of fish feeding systems is bound to improve efficiency in aquaculture farms.

\subsection{Review of Automatic Fish Feeding Techniques}

Fish farming is a multi-billion industry that has evolved to incorporate technology into the management that includes smart feeding systems. Towards this end, a comparison of several feeding systems is vital to establish the operating mechanisms of the structures under review. To begin with, the Sustainable Aquaculture Feed System has been equipped with a vision sensor machine that is used to estimate the amount of feed required by the livestock being reared, which prevents waste of nutrients availed to the fish [6]. Notably, the system can count the number of fish that is critical in determining the amount of food required by the fish. In relation, the technology can be used to deduce the size of the fish, which is essential in formulating the feeding program to ensure that the amount released is sufficient. Even further, the approach can detect the gender of the marine species since they require different nutritional amounts.

Finally, the model can be used to identify the type of fish in the farm, which is used to inform the feeding program. The system has employed the bio-scanner to undertake the requirements as mentioned above with considerable success. The SAFS system has several components that include both hardware and software processing elements, which include a camera, Bluetooth receiver, and input devices. The hardware part consists of a camera, sensors, and the feeder system [6]. The incorporation of a graphical user interface is essential since it provides data analysis structure that is used to study patterns in the tanks [7]. The use of Bluetooth is designed to ensure information is relayed to the required area electronically, which allows that graphic images can be shared within system components. The inclusion of a timer is critical to the success of the feeding system since it ensures the fish are fed at the appropriate time with the video having three frames image per second.

On the other hand, the development of an automatic feeder system has led to the creation of a smart system, which is controlled using artificial intelligence. The idea is to monitor the feeding process continuously utilising the interface. The device uses the Global Standard for Mobile Communication, which enables the firm to track the progress of the feeding program remotely [8]. Ideally, the invention is applied to issue commands to the feeding program in real-time. Consequently, the system can operate with minimal human intervention resulting in a fully automated product. The inclusion of a central processing unit is essential since it receives all inputs in the system that is processed before being used to issue commands in the smart feeding program. The system has a temperature sensor, which is used to analyse the conditions in the water. It is imperative to state that water heat is critical in aquaculture since it influences the deterioration of either the feed, which might affect positively or negatively the nutritional content. The inclusion of a camera is designed to ensure digital images of the fish stock can be monitored using the structure [9]. The camera enables the farmer to identify the number of fish, sex, size, and number, which inform the amount and type of feed to be released into the farm. In fact, the system has an $80 \%$ accuracy, which is good considering that the smart feeding industry is relatively nascent. Being able to deduce the physical characteristics of the fish enables the farmer to release the correct amount of feed, which reduces wastage, especially in controlled aquaculture. Time management is another vital element that has been considered in the design since the fish stock must be fed at appropriate times to ensure optimal nutritional value is derived from the feeds. 
Table 2. Comparison of Different Fish Feeding System

\begin{tabular}{ccccc}
\hline \hline Market & Sizing & Feeding & Analysis & Tracking \\
\hline Automatic Computer Vision Systems for Aquatic & Yes & & Yes & Yes \\
Research[10] & & & & \\
Sustainable Aquaculture Feed System [6] & Yes & Yes & Yes & Yes \\
The Automatic Feeder System [8] & Yes & Yes & Yes & Yes \\
Solar Powered Automatic Shrimp Feeding System [11] & & Yes & & \\
\hline
\end{tabular}

The use of Automatic Computer Vision Systems for Aquatic Research is an efficient system that has been developed to facilitate feeding of fish. The structure addresses several critical issues, which include the incorporation of a sizing mechanism that can be used to inform the amount of feed to be released into the farm. Further, the identification of fish species, specifically the zebra fish is another critical component of the system that determines the type of feeds to be used in feeding the marine animal. Again, the automated system enables the farmer to analyse the behaviour of larval fish in the farm, which can deduce trends and patterns that can be used to develop a feeding program. The system is equipped with a camera and computer processing facility that can produce information [10].

In summation, depleting fish stocks in the ocean have led to the development of aquaculture farms that require substantial amounts of feeds. The creation of fish feeding systems been automated to ensure the process is efficient. Notably, manual feeding is wasteful and unable to detect the nutritional needs of marine animals rightly. The Solar Powered Automatic Shrimp Feeding System has integrated several components that ensure shrimps are fed at specific intervals. The structure uses solar energy to release food into the tank, which improves energy efficiency. To conclude, the automation of a feeding system in fish farms will enhance the productivity of the products.

\subsection{Challenges and Opportunities}

The principal risks of aqua farming are fish diseases, technical malfunctions in the work of equipment for feeding fish, saturation of water with oxygen, substandard feed, and others [12]. Additionally, usually, the feeding of fish is between 50\% and $80 \%$ of the overhead costs of a fish farm [12]. Nutrition is a manual task, so it is an immeasurable and inaccurate method with such results as overfeeding and underfeeding of fish. Overfeeding means that the majority of food goes to waste, and it infringes the financial part of aqua farming, the surrounding the farm marine environment, and the health of the fish. On the other hand, the lack of feeding leads to famine and the gradual dying of fish. Moreover, some challenges may be faced with the course of this project. These challenges may include:

1. Fish Size: Fish of various sizes take food differently. Small fish are more passive in the fight for food because of their size, so they get insufficient food. Indeed, many fish are shy, and they are at a far distance from the bold fish, which get food together. Shy fish receive an inadequate amount of food, therefore, improving the method of feeding fish is a critical point in the successful operation of aqua farms. The development of an automatic intelligent feeding system is significant for solving these problems and distributing the right amount of feed using sensors that measure the appetite of fish.

Nutrition and feeding have a significant effect on the health of fish. It affects their behaviour and response to different environmental conditions. Since fish of different size have different 
feeding patterns, it is prudent to learn their behaviour which helps the farmer to prepare an effective fishing schedule. According to Lall and Tibbetts, fish behave differently depending on the feeding habit, feeding method as well as the frequency of feeding [13]. The proposed system will be able to analyse the food preference of a shoal for optimal growth.

2. Fish Behaviours: The behaviour of fish associated with nutrition depends on their type, size, and sometimes on their sex [1]. Fishes usually eat other fishes or plants. Even representatives of fish species, which do not belong to predators, eat small fish when their size is equal to the preferred food. Indeed, adult fish mostly eat caviar and fry if they find it in the nearest area. Moreover, fishes use to dig in the ground. Some fish directly get their own food in the uppermost layer of soil, while others sift the ground through the gills and during this process sometimes absorb reasonably large pieces of soil.

According to Lovell, of all the spectrum of behavioural reactions manifested by fish, the main one is the behaviour associated with nutrition [1]. Food behaviour is a complicated process of a successive change of individual behavioural phases and acts from the moment of obtaining information about the presence in the environment of food objects before deciding whether to seize or reject them [1]. The first phase of the nutrition behaviour of fish is the rest, which is such state of fish when it does not react to the external food stimuli. It is common for the majority of species, and it happens due to various causes, including illness, the closeness of spawning period, wintering, etc. The second phase is the readiness for obtaining the signal on food availability. The third phase is an obtaining signal on food availability. In the process of scanning the water reservoir, the fish eventually discovers the signal emanating from the food object. In the process, all sensory systems of fish are involved, so the signs received can be variable in nature and have different intensity and direction. The next phase is the search and detection of the source of food. Therefore, among the whole spectrum of available signals, the fish chooses one. After the food signal is selected, fish start to search for the source. The last phase is the determination of the suitability of food.

Moreover, Abdallah and Elmessery have stated that some fish used to eat only in open spaces [14]. Others, which are shyer, hide in the clefts anticipating the best moment to swim out. Cereal fishes spend a very long time feeding to satisfy their nutritional needs, while predatory species like eels are not eaten every day. These varied ways of feeding become apparent in the artificial ponds and require attention. Otherwise, the fish will not survive. Indeed, small fish may not receive enough feed because they have shy behaviour patterns. According to Abdallah and Elmessery, small fish may not appear near the sensors of hunger control, so they may remain hungry, and would have to eat a minimum amount of snacks after huge fishes [14]. Moreover, AlZubi thinks that this intelligent system of feeding fish requires the significant campaign of advertisement and popularisation, since the majority of farmers are not accustomed to the idea of using technology in their production process [5]. In the beginning, many of them were resistant to adopting the application, but education and training, as well as a rental system, allowed them to spend less money and give them the real evidence [5].

3. Fish Tracking: According to Al-Jubouri, the current fish tracking methods require the tagging of an individual fish which is quite challenging [10]. This calls for the need of advanced system whereby the non-contact method of recognising a particular free moving fish has been developed. The system does not only reduce the time for tagging process but also offer a realtime recognition technique. The computer-aided tool in its different models provides a successful solution for analysing the behaviour of fish, their feeding habit, and size. Studies to find out whether fish have the capacity painful stimuli and associated discomfort have been faced with a challenge of ethical restriction. Larval zebra has been used instead since their responses are similar to those of the adults. It is therefore advisable to consider the ethical 
suitability of a given system that affects the behaviour of fish or any other animal being used in the study.

\section{AIMS AND OBJECTIVES}

The system should accomplish the task in three stages. The first stage in the algorithm is the object detection where the subject under the study is identified. The object is then tracked and monitored closely where the activities are recorded. For this case, a fish will be identified and monitored. The collected data is processed and a conclusion drawn from the analysis. Three stimulation techniques can be used in the study; they include thermal, electrical and chemical stimulation. Electrical stimulation is the most opposed technique among the three since it inflicts pain on the object under study. It is therefore used in a limited number of studies.it is also associated with unpredictable behavioural reactions. It is also not easy to capture the movement of small fish with this method due to the transparency in their body [10].

\subsection{The Aims of This Study}

In this study, to achieve the aims of study the system smart fish feeding. This will encompass:

1. In order to precisely identify and measure the amount of feed for each fish

2. Minimising the impact of traditional feeding mechanisms

3. Testing the fish preference for type of feed

4. Minimising the feed waste and maximising the conversion rate of food products

\subsection{Objectives}

The Objectives of the project can be defined as:

1. Optimising diet for fish

2. Developing a new way to keep the fish tank clean

3. Developing new ways of modulating data onto a smart fish feeding system

4. Determining the possibilities of feeding fish system recreation using digital data

\section{EXPECTED MATERIALS AND METHODS}

\subsection{Design considerations}

This project will provide the estimation of the preference fish feeding by using ways to observe fish behaviour and response to the type of feed. This project require tank is separated into two areas; Living Area and Feeding Area which is the diet area. Living Area that is comfortable to fish contains gravel and plants, however, Feeding Area is less comfortable because it is less natural and bare to fish (Fig.2). The design shows the recirculation system which consists of a water filter and pump that is used for filtration and measure the amount of waste of feed. Furthermore, the sensors may not always fully reflect the state of the fish. Many water parameters should be measured: $\mathrm{pH}$, the temperature, salinity, dissolved oxygen, ammonium, the transparency, the suspended solids, nitrates, the total nitrogen or match soluble reagent, among others [15]. The smart fish feeding architecture comprises of a few components, which includes the hardware design, and the software algorithm with the database of the fish. 


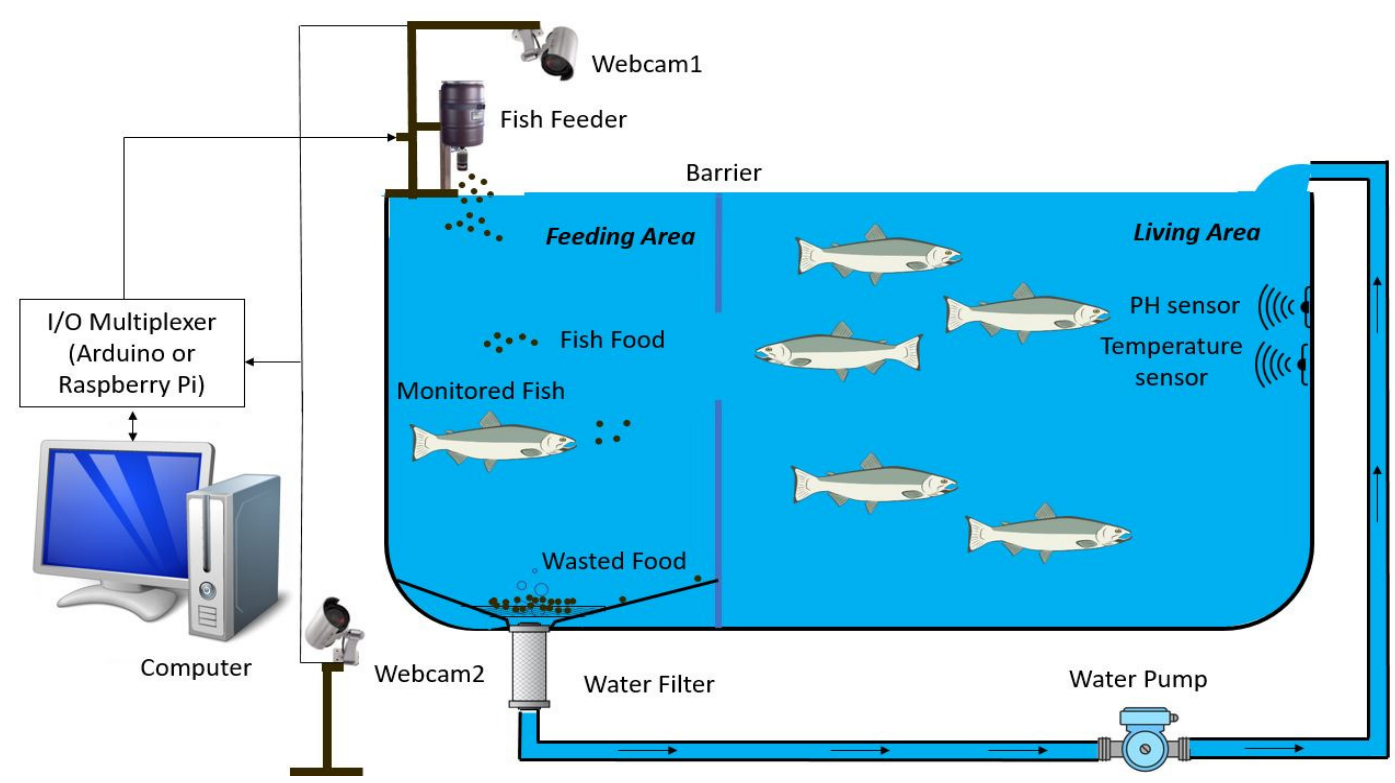

Figure 2. The smart fish feeding system setup

\subsection{Methodology}

Modern methods of fish feeding include an intelligent feeding system based on fish behaviour and extend to speed respond fishes toward one kind of feed to minimise the impact of traditional feeding mechanisms. The proposed mechanism of nutrition interacts, recognises and reacts to the activity of fish [5]. Such feeding system feeds fish at their request, regardless of the time of the day. Figure 3, shows the block diagram of the system measure the Feeding Efficiency (FE), and Specific Growth Rate (SGR, \% body weight per day) which reflects fish respond development of the given feed.

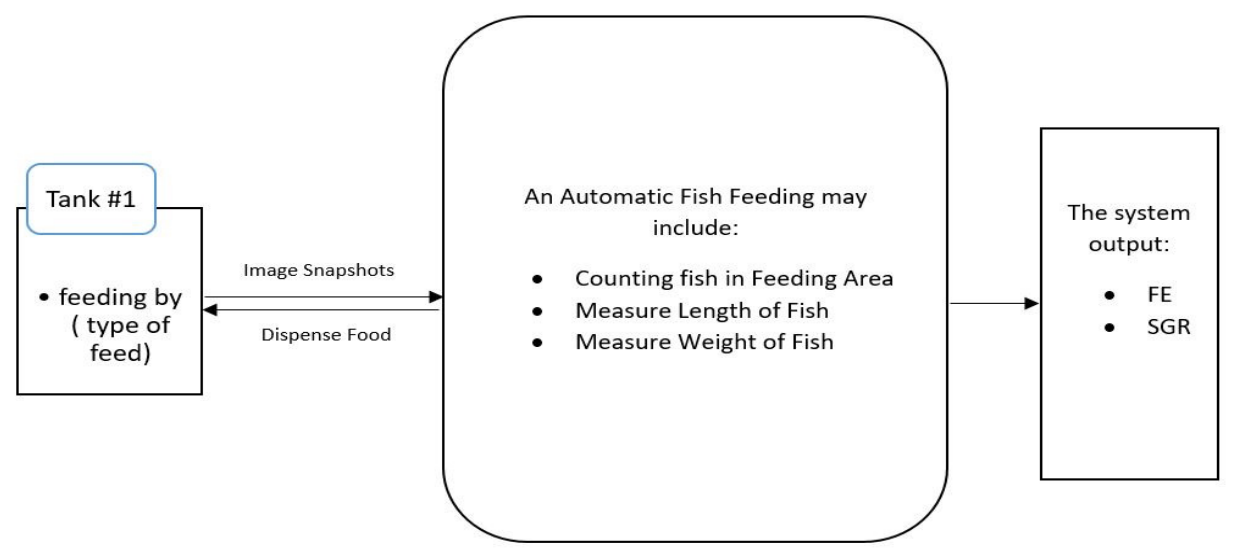

Figure 3: Block diagram of the proposed system

Where $\mathrm{N}$ number of tanks fish feeding which each tank feeding by one type of different feed. The system connects to each tank that has the same volume of feed. The system could study the preference testing for fish. Moreover, this design system is used to study the behaviour and growth of fish toward a certain food. First of all, assume the fish does not have any knowledge about the new fish feeding mechanism. In order to introduce the system to fish, the food is dispensed based on schedule plan similar to traditional feeding mechanism called Adaptive 
Session. In this session, the fish feeding must be in the Feeding Area to learn fish the smart feeding system. The smart fish feeding is running independently from the beginning of the experiment in order to quantify fish behaviour and responses. When the fish show the high level of learning the adaptive session, the system switch to the smart fish feeding system. A greater learning factor is weighted using fish learning index when a more the system depends on the behavioural feeder since actions from scheduled and behavioural feeders, which reflects fish behaviour development during the adaptive session [5]. Further, the volume of feed consumed, the number of time for fish seeking the food and the growth of fish is a great reflection to study the extent of their response to a given feed through period time. The proposed system consists of two sections: the Hardware and the Software.

\subsubsection{Hardware:}

The hardware of smart fish feeding system consists of a fish tank and three main components listed as below:

1. Two Webcams: The webcam has a low cost for the farmer and equipped with various devices to improve the quality of recording [5]. The first webcam is fixed over the Feeding Area to take a top view of the fish activities. Moreover, the image snapshot from webcam1 for counting and measure the length of fish. The second webcam is fixed in the front side of the tank to take image snapshot to get measure the distance between the object and the webcam 1 and the estimated weight of an object by measure the Girth of fish.

- The Girth $(G)$ of the fish was calculated using the following formulas:

$$
G=2 \pi \sqrt{\frac{\mathrm{a}^{2}+\mathrm{b}^{2}}{2}}
$$

Where $a=$ semi-major axis length of an ellipse and $b=$ semi-minor axis length of an ellipse.

- The Estimated Weight $(W)$ of the fish modified [16]

$$
W=\frac{(G)^{2} \times L}{800} \times\left(\frac{25}{64}\right)^{3}
$$

Where $L$ is the length $(\mathrm{cm})$. Usually, a black and white image at greater depths is better than a colour image. Black-and-white image has the advantage over colour views of working in troubled waters with low transparency (Fig.4).

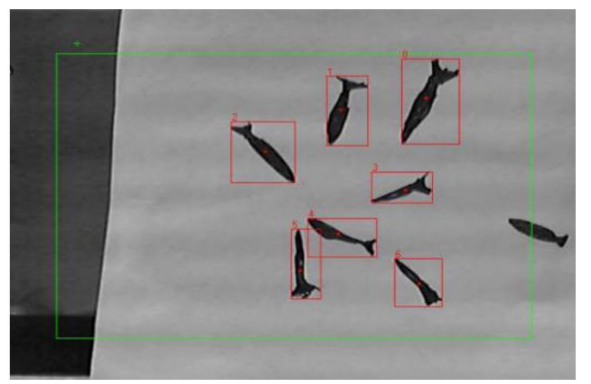

Figure 4. An example of shoot made by Logitech 720p webcam [6] 
2. Fish Feeder: The fish feeder is an automatic dispenser that is a horizontal cylindrical food container with an adjustable gap at one end. The food container should be connected to a stepper motor, which can control it by I/O multiplexer such as Arduino or Raspberry Pi depend on the data from the webcams. Rotating the container $360 \square$ is dropped in the tank a small portion of food.

3. Interface Circuit: The interface circuit consists the Arduino or Raspberry Pi and hardware PC. The webcams and the fish feeder are connected to an interface circuit. The interface circuit allows the software algorithm to control the fish feeder as a response to the fish activities.

\subsubsection{Software:}

The software of the operation of such an intelligent feeding system is quite simple. After determining the relative hunger of the fish through observe fish in the Feeding Area, the loaded machine releases the configured number of feeds depends on the number of fish immediately and sends real-time image snapshots directly to PC (Fig.5).

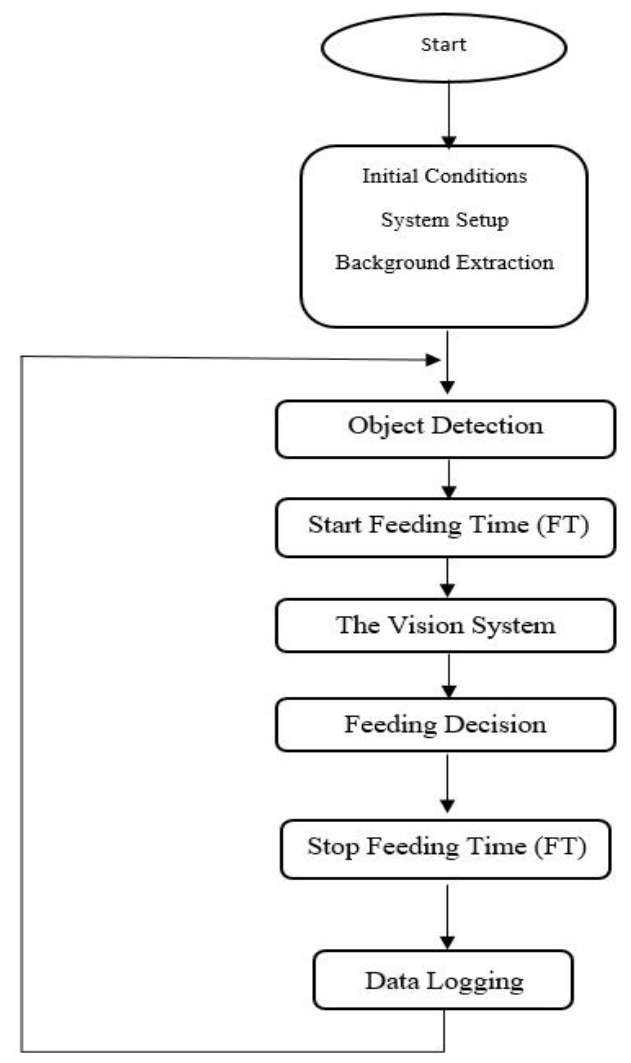

Figure 5. Flowchart of the proposed system algorithm

Based on the analysis information about the number and size of fish and their behaviour which convey by the images. The PC can draw conclusions about the correlation of these indicators. The image snapshots are the input source for the system which can analysis by using:

1. Graphical User Interface (GUI): The Graphical User Interface (GUI) the software could develop using MATLAB which is a multi-paradigm numerical is computing environment developed by Math Works. It allows matrix manipulators, plotting of 
functions and data, implementations of algorithms, a creation of UIs and interfacing with text-based programs written in various languages such as $\mathrm{C}, \mathrm{C}++$, Java and Python [17]. The developed software enables end-users to access:

- Event system

- Control of webcams

- Control the feeding system

- Counting fishes in the feeding area

- Recording updating rate i.e. length and weight of fish

2. Object Detection: The object detection algorithm has a fundamental influence on the performance of the counting and sizing systems. The system based on fish detection in the Feeding Area.

3. Feeding Time (FT): The system measure the timing of fish feeding determines the night or day mode of the system. Recording the timing of feeding is important to calculate the volume of feed which dispenses. Further, calculation timing of feeding helps to collect information about the time behaviour of fish during feeding as well as the duration of each fish feeding.

4. The Vision System: The proposed methodology consists of nine distinct stages: image acquisition, image pre-processing, image segmentation, feature extraction, classification algorithm, and number, length, and girth of the fish estimation. Figure 6, shows the block diagram of the proposed algorithm and are described as follows [18].

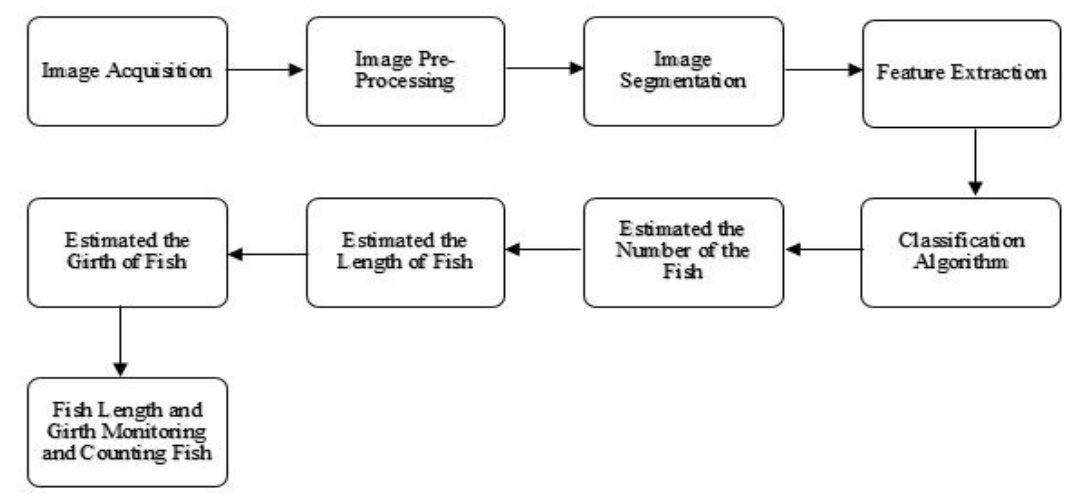

Figure 6. Proposed methodology of the vision system

i. Image Acquisition (Two webcams-Frames)

ii. Image Pre-Processing (Image Colour- Camera distance- Background extraction)

iii. Image Segmentation (Thresholding-Morphological operation- Watershed segmentation)[18]

iv. Feature Extraction (Extract size and shape feature)

v. Classification Algorithm (the sizing algorithm and counting algorithm)

vi. Estimated the Number of the Fish

vii. Estimated the Length of fish

viii. Estimated the Girth of fish

ix. Fish Length and Girth Monitoring and Counting Fish 
5. Feeding Decision: The feeding decision is based on the number of fish in the Feeding Area which calculated by the vision system. If the number of fish value exceeded one then feeding signal will be issued to the I/O multiplexer such as (Arduino or Raspberry Pi controller) to turn the feeder on. Moreover, the feeding decision based on the relative hung which is determining the overfeeding and underfeeding. This system control variable volume of feed consumed that is calculated from the amount of waste in the filtration system from each feeding.

6. Data Logging: During the specific long time, every update cycle is logged for further analysis which is in night or day mode. The proposed system connect to the PC to logging and analysis the data. The data shows specific growth ratio (SGR) and the feeding efficiency (FE) during the period time. Moreover, the system exists the volume of feed consumed which are accurate data to show the preference feed for fish because the system dispenses the valid amount of stimulating feed by reducing the amount of waste feed. The Feeding Efficiency (FE) and Specific Growth Rate (SGR, 1\% body weight per day) were calculated using the following formulas:

$$
\begin{gathered}
F C R=\frac{M}{m^{*}} \\
F E=\frac{1}{F C R}
\end{gathered}
$$

Where $F C R$ is Feed Conversion Ratio, $M$ mean the mass of food consumed (g) and $m^{*}$ is the increase in mass of animal produced $(\mathrm{g})$

$$
S G R=\frac{10^{2}\left(\ln W_{f}-\ln W_{i}\right)}{t}
$$

Where $W_{\mathrm{f}}$ and $W_{\mathrm{i}}$ are the final and the initial body mass (g) respectively, and $t$ is the total number of days between the two measuring days [19].

\section{CONCLUSION}

Consequently, aquaculture is a rapidly growing sphere of farming, which provokes the active development of technology in this area. Fish feeding is an important component of fish farming, so the inventions for improving feeding are relevant and requested. One such invention is the smart fish feeding system, which can monitor food behaviour of fish using sensors. As an illustration, one of such sensors is the webcam that can capture fish movements. A fully automatic feeding system should be developed to understand fish's food behaviour in a dense aquaculture tank. Such a system should have the ability to classify the activity of fish food intake along with the continuous detection of the fish preference of excessive raw materials. Moreover, the system should provide valuable information for controlling the feed in the food tank. The algorithm of the system needs improvement constantly in order to provide information on how fishes are active in numerical value and use detection of the boundaries of feeding for the more in-depth understanding of the beginning of the feeding and its termination. This system should also facilitate the creation of statistics on the increase of fish in order to develop computational and quantitative approaches to a comprehensive understanding of the growth of fish. 


\section{REFERENCES}

[1] Lovell, Tom, Nutrition and Feeding of Fish. Springer Science \& Business Media, 2012.

[2] The Future of Agriculture, The Economist, 2016, http://www.economist.com/technologyquarterly/2016-06-09/factory-fresh. Accessed December 15, 2017.

[3] BMA, Hasan, and B Guha, Optimization Of Feeding Efficiency In Semi-Intensive Farming System For Sustainable And Cost Effective Production Of Penaeus Monodon Fabricius. Journal of Aquaculture Research\& Development, vol 3, no. 6, 2012, OMICS Publishing Group, doi:10.4172/21559546.1000149.

[4] Conti, Stephane G., Philippe Roux, Christian Fauvel, Benjamin D.Maurer and David A.Demer. Acoustical Monitoring of Fish Density, Behavior, and Growth Rate in a Tank. Aquaculture, vol. 251, no. 2-4, 2006, pp. 314-323. Elsevier BV, doi:10.1016/j.aquaculture.2005.06.018.

[5] AlZubi, Hamzah S., Waleed Al-Nuaimy, Jonathan Buckley and Iain Young. An Intelligent BehaviorBased Fish Feeding System. 2016 13Th International Multi Conference on Systems, Signals \& Devices (SSD), 2016, IEEE,doi:10.1109/ssd.2016.7473754.

[6] Jer-Vui Lee, Joo-Ling Loo, Yea-Dat Chuah, Pek-Yee Tang, Yong-Chai Tan and Wei- Jian Goh. The Use of Vision in a Sustainable Aquaculture Feeding System. Research Journal of Applied Sciences, Engineering and Technology, vol 6, no. 19, 2013, pp. 3658-3669.

[7] Faizan Hasan MUSTAFA, Awangku Hassanal Bahar Pengiran BAGUL,Shigeharu SENOO, Rosita SHAPAWI A Review of Smart Fish Farming Systems. Journal of Aquaculture Engineering and Fisheries Research, vol. 2, no. 4, 2016.

[8] Md. Nasir Uddin, Mm Rashid, Mg Mostafa, Belayet H, Sm Salam, Na Nithe, Mw Rahman \& A Aziz. Development of Automatic Fish Feeder. Global Journal of Researchers in Engineering: A Mechanical and Mechanics Engineering, vo. 16, no. 2, 2016.

[9] Zelda Dunn. Improved Feed Utilization in Cage Aquaculture by Use of Machine Vision. University of Stellenbosch, 2008.

[10] Al-Jubouri, Quassay Salim, Automatic Computer Vision Systems for Aquatic. University of Liverpool, Accessed September 2017.

[11] Dindo, T.Ani, Meryll, Grace F.Cueto, Niño, Jerome G.Diokno and Kimberly, Rose R.Perez, Solar Powered Automatic Shrimp Feeding System. Journal of Multidisciplinary Research, vol.3, 2015, pp. 152-159.

[12] Costa, C., A.Loy, S. Cataudella, D.Davis and M.Scardi Extracting Fish Size Using Dual Underwater Cameras. Aquacultural Engineering, vol 35, no. 3, 2006, pp. 218-227. Elsevier BV.

[13] Lall, S P, and S M Tibbetts, Nutrition, feeding, and behavior of fish. The veterinary clinics of North America. Exotic animal practice. U.S. National Library of Medicine, May 2009, www.ncbi.nlm.nih.gov/pubmed/19341962.

[14] Abdallah, S. E. and W. M. Elmessery, an Automatic Feeder with Two Different Control Systems for Intensive Mirror Carp Production. Journal of Agricultural Engineering and Biotechnology, 2014, pp. 36-48. Bowen Publishing Company, doi: 10.18005/jaeb0203002.

[15] Miguel Garcia-Pineda, Sandra Sendra, Gins Lloret, Jaime Lloret. Monitoring and Control Sensor System for Fish Feeding in Marine Fish Farms. September, 2011. 
[16] Mika, Kurkilahti, Magnus Appelberg, Trygve Hesthagen and Martti Rask, Effect of fish shape on gillnet selectivity: A study with Fulton's condition factor, Journal of Fisheries Research. vol 54, no. 3, 2002, pp. 153-170. Elsevier BV.

[17] William J. Palm. Introduction of MATLAB for Engineers, University of Rhode Island, book Third Edition,1944.

[18] Ibrahim Aliyu, Kolo Jonathan Gana, Aibnu Abiodun, James Agajo, Abdullahi M, Folorunso T , and Mutiu A, A Proposed Fish Counting using Digital Image Processing Technique. Journal of Science, Technolology and Education (JOSTE), Federal University of Technology, 2017, pp. 36-48. Bowen Publishing Company,ISSN:2277-0011.

[19] Sandie Millot, Jonatan Nilsson, Jan Erik Fosseidengen, Marie-Laure Begout and Tore Kristiansen, Evaluation of self-feeders as a tool to study diet preferences in groups of Atlantic cod (Gadus morhua), 2012.

\section{AUTHORS}

Mohammed M. Alammar received MSc in Electrical Engineering from University of Dayton, USA in 2016.He is a lecturer at King Khalid University, Abha, KSA. He is currently pursuing Ph.D. degree with University of Liverpool, Liverpool, UK. His research interest include Image Processing, Signal Processing and Embedded Systems.

Contact:

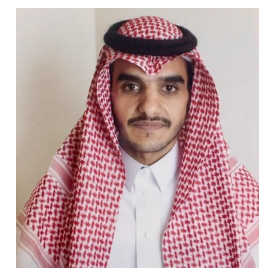

E-mail: m.m.alammar@liverpool.ac.uk

E-mail: mma-022@hotmail.com 